\title{
Semantic congruity in symbolic comparisons: Salience, expectancy, and associative priming
}

\author{
MARC MARSCHARK \\ University of North Carolina, Greensboro, North Carolina 27412
}

\begin{abstract}
An expectancy interpretation of semantic congruity effects suggests that in symbolic comparisons involving the typical comparative-then-stimuli paradigm, the comparative acts as a cue in priming memory for related stimuli. A recent study by Holyoak and Mah (1981) presented evidence purported to disconfirm this hypothesis insofar as a congruity effect also was obtained when the stimuli preceded the comparative. The present study showed the stimulicomparative effect to be a consequence of the pairing of stimuli with particularly salient comparatives such that the former could serve the cuing function. This finding is consistent with the expectancy hypothesis in emphasizing the role of a flexible encoding process but inconsistent with the view that only comparatives can create expectancies in symbolic comparisons.
\end{abstract}

One of the more robust findings in recent symbolic comparison studies is that reaction times for comparing stimuli lying toward one extreme of a dimension are faster when the judgments involve the same-pole comparative than when they involve the opposite-pole comparative. Given the comparative "smaller," for example, subjects respond faster to pairs like "ant flea" than to pairs like "cow elephant," whereas the reverse is true given the comparative "larger." Among the several theoretical interpretations of this semantic congruity effect is an expectancy hypothesis described by Marschark and Paivio $(1979,1981) .{ }^{1}$ That proposal derived from their observation that robust congruity effects were obtained only in studies employing comparative-thenstimulus (C-S) presentation orders (e.g., Banks, 1977; Banks \& Flora, 1977, Experiment 2; Banks, Fujii, \& Kayra-Stuart, 1976; Holyoak \& Walker, 1976). Marschark and Paivio (1979) suggested that congruity effects in symbolic comparisons are linked to the C-S ordering insofar as presentation of the comparative first creates a situation in which the subject can "expect" some set or range of possible stimuli. ${ }^{2}$ The results of their experiments supported the expectancy hypothesis.

The expectancy hypothesis was applied to perceptual comparisons by Marschark and Paivio (1981). In a series of six experiments, they found that congruity effects were not obtained in purely perceptual conditions but

This research was one of several projects conducted by the UNC-G Psychology Language Research Group. Diane Praetorius and $J$ udy Keating were the group members primarily connected with this project, having collected the data for Experiment 2. Carole Greer assisted in the data collection and analyses of Experiment 1, and Reed Hunt provided several useful comments on an earlier manuscript. The project was supported by a grant from the University of North Carolina at Greensboro Research Council. Correspondence should be sent to Marc Marschark, Department of Psychology, University of North Carolina at Greensboro, Greensboro, North Carolina 27412. depended on subjects' using symbolic information from memory. On the basis of this and their earlier findings, Marschark and Paivio suggested the congruity effect to be essentially a priming phenomenon in which the comparative in the bipolar, C-S paradigm acts as a cue for the activation of potential stimuli in memory. Over trials, such activation would sometimes be correct, yielding relatively short response latencies, and sometimes be incorrect, yielding relatively long latencies; a congruity effect thus would be obtained. This suggestion also was consistent with Marschark and Paivio's (1979) observation that the congruity effect typically is not obtained in experiments involving the alternative, stimulus-then-comparative (S-C) paradigm (e.g., Banks \& Flora, 1977, Experiments 3-5); Marschark \& Paivio, 1979, Experiment 2; Moyer \& Landauer, 1967). They suggested this to be due to the fact that to-be-compared stimuli in this paradigm are not preceded by a potential cue (Marschark \& Paivio, 1979, p. 176).

While all of the available evidence supports the hypothesis that C-S and S-C paradigms typically involve somewhat different processing schemes, both Marschark (1982) and Marschark and Paivio (1981) have pointed out that from the expectancy hypothesis, a congruity effect in the S-C paradigm is logically possible. Specifically, if the association between a stimulus pair (e.g., "elephant whale") and a particular comparative were strong enough to be activated on presentation of the stimuli, a priming-based congruity interaction might be obtained.

In a study designed to test the original formulation of the expectancy hypothesis, Holyoak and Mah (1981) presented findings relevant to this point. Marschark and Paivio (1979, Experiment 2) had failed to obtain a congruity effect using the S-C paradigm and cited that finding as support for the expectancy hypothesis. Holyoak and Mah, in contrast, attributed Marschark and Paivio's failure to obtain the effect to their use of a 
3-sec delay between presentations of the stimuli and the comparative. It was suggested that this would have allowed subjects to make the comparisons prior to seeing the comparative: "If subjects have already completed the comparison process before the comparative is presented and the locus of the congruity effect is in the comparison process, that effect will necessarily be eliminated .... [The expectancy] hypothesis suggested that the comparative influences initial encoding of the items but not the actual comparison process. This claim is not being tested if subjects are allowed to complete the comparison process before the comparative is presented"' (Holyoak \& Mah, 1981, p. 199).

Although this criticism may be well founded (see Banks \& Flora, 1977, p. 286; Marschark \& Paivio, 1979 , p. 181), it is unlikely to account for Marschark and Paivio's results. If their subjects had completed their judgments (during the delay) often enough to eliminate the congruity effect, a symbolic distance effect, which arises from the comparison itself, should not have been obtained. In fact, the distance effect was highly reliable.

Marschark and Paivio (1979) accounted for the absence of congruity effects in stimulus-first tasks by noting that the stimulus expectancies created by the comparative in the C-S paradigm would not be induced in the S-C paradigm, because the stimuli already would have been encoded when the comparative was presented. Holyoak and Mah (1981), however, interpreted this as a statement that no expectancies of any sort could be induced when the stimuli precede the comparative (cf. Marschark \& Paivio, 1981). This is rather more extreme than was intended by Marschark and Paivio's statement, but Holyoak and Mah's (1981) interpretation, nevertheless, led them to an interesting test of the expectancy hypothesis. They used an S-C paradigm in which subjects were allowed to encode but not compare the stimuli before a comparative was presented. This was accomplished by intermixing the eight comparatives "fierce," "meek," "large," "small," "smart," "dumb," "fast," and "slow" in a series of animal comparisons. Contrary both to their operational definition of the expectancy hypothesis and to the general pattern of findings in the literature, Holyoak and Mah obtained a reliable congruity effect. That result, however, does not bear necessarily on the semantic priming interpretation of the congruity effect detailed by Marschark and Paivio (1981). That position, as described above, would suggest that Holyoak and Mah's congruity finding must have resulted from their stimulus pairs' being particularly salient with respect to the dimensions on which they were judged. Such a situation, in fact, is not unlikely, since when selecting pairs for such a task, it is natural (at least according to the expectancy hypothesis) for experimenters to select stimuli characteristically thought of as extreme on that dimension. Pairs like "elephant whale," for example, might be expected to yield a reliable congruity effect when compared on the salient dimension of size but not on other, nonsalient dimensions such as intelligence or ferocity.

An interaction of salience with the congruity effect would have some interesting implications. With respect to the issues discussed above, such a finding would limit the 1979 formulation of the expectancy hypothesis on which Holyoak and Mah's (1981) study was based, but at the same time, it would provide evidence convergent with earlier results indicating the congruity effect to be a semantic priming phenomenon (Marschark \& Paivio, 1981, Note 1). More generally, a salience-congruity interaction would provide new information concerning the symbolic comparison process insofar as it would indicate the relevance of associative information between symbolic stimuli and dimensions on which they are subsequently evaluated. If associative priming is sufficient to determine the presence or absence of congruity effects in this task, examination of its role in accessing attribute information in other paradigms might reveal much about the way that symbolic stimuli activate their referents in memory.

\section{EXPERIMENT 1}

The first experiment was a normative study designed to provide information concerning the strengths of associations between Holyoak and Mah's (1981) animal stimuli and the dimensions on which they were compared. Such information is not recoverable from their normative relative magnitude data of animal ferocity, size, intelligence, and speed. The fact that an elephant is a relatively fierce animal according to their norms (6.75 on a 10-point scale), for example, does not indicate fierceness to be a particularly salient characteristic of elephants. Similarly, the low rating of a snail's intelligence (.24) need not indicate a strong association between snails and the comparative "dumber."

\section{Method}

Stimuli and Procedure. The stimuli were the 79 animal names ("human" was omitted) used by Holyoak and Mah (1981). These were listed in alphabetical order on four pages of a test booklet. Each animal was followed by four columns headed "fierce/meek," "smart/dumb," "large/small," and "fast/slow." Subjects were informed that "these dimensions correspond to attributes that people often ascribe to animals. In this task, we would like you simply to decide which of the eight attributes best characterizes each animal." Subjects selected one adjective per animal and then wrote it to the right of each name in the appropriate column. The experimenter emphasized that responses should reflect each species in general rather than a particular member that the subject might have had experience with (e.g., "Lassie" or the family cat). The task was self-paced.

Subjects. A total of 56 University of North Carolina at Greensboro undergraduates participated as volunteers. They were tested in three groups following regular meetings of their intermediate-level psychology courses.

\section{Results and Discussion}

The frequencies with which each adjective was attributed to each animal are shown in Table 1. Those 
Table 1

Frequencies of Primary Attribute Associations for 79 Animal Names ( $=56$ )

\begin{tabular}{|c|c|c|c|c|c|c|c|c|}
\hline \multirow[b]{2}{*}{ Animal } & \multicolumn{8}{|c|}{ Attribute } \\
\hline & Fierce & Meek & Smart & Dumb & Large & Small & Fast & Slow \\
\hline Alliga tor & 44 & 0 & 0 & 0 & 4 & 0 & 0 & 7 \\
\hline Anteater & 0 & 12 & 4 & 19 & 3 & 7 & 2 & 9 \\
\hline Antelope & 1 & 2 & 2 & 0 & 11 & 0 & 38 & 0 \\
\hline Armadillo & 4 & 9 & 5 & 7 & 2 & 17 & 1 & 10 \\
\hline Badger & 22 & 4 & 4 & 4 & 0 & 15 & 6 & 0 \\
\hline Bat & 5 & 0 & 7 & 5 & 0 & 26 & 11 & 0 \\
\hline Beaver & 1 & 3 & 34 & 2 & 0 & 6 & 4 & 4 \\
\hline Boar & 28 & 2 & 2 & 8 & 7 & 4 & 2 & 1 \\
\hline Bobcat & 30 & 1 & 4 & 0 & 1 & 2 & 16 & 0 \\
\hline Buffalo & 2 & 0 & 0 & 3 & 50 & 0 & 0 & 0 \\
\hline Bull & 21 & 1 & 0 & 6 & 26 & 0 & 0 & 1 \\
\hline Camel & 0 & 8 & 1 & 9 & 15 & 1 & 0 & 20 \\
\hline Canary & 0 & 10 & 7 & 2 & 0 & 36 & 0 & 0 \\
\hline Cat & 1 & 11 & 25 & 4 & 0 & 8 & 5 & 0 \\
\hline Chicken & 0 & 3 & 0 & 38 & 0 & 8 & 5 & 0 \\
\hline Chimpanzee & 1 & 2 & 46 & 3 & 0 & 1 & 2 & 0 \\
\hline Chipmunk & 1 & 6 & 8 & 3 & 0 & 32 & 5 & 0 \\
\hline Cow & 0 & 8 & 0 & 20 & 19 & 1 & 0 & 7 \\
\hline Coyote & 14 & 1 & 19 & 2 & 0 & 3 & 17 & 0 \\
\hline Crab & 7 & 0 & 1 & 3 & 0 & 29 & 6 & 9 \\
\hline Deer & 0 & 17 & 2 & 0 & 1 & 0 & 34 & 0 \\
\hline Dinosaur & 4 & 0 & 0 & 10 & 40 & 0 & 0 & 0 \\
\hline Dog & 1 & 1 & 44 & 3 & 1 & 0 & 5 & 0 \\
\hline Dolphin & .3 & 1 & 49 & 0 & 1 & 0 & 2 & 0 \\
\hline Donkey & 0 & 1 & 0 & 38 & 1 & 0 & 1 & 15 \\
\hline Dove & 0 & 29 & 0 & 0 & 0 & 19 & 6 & 1 \\
\hline Duck & 0 & 15 & 0 & 11 & 0 & 19 & 2 & 9 \\
\hline Eagle & 16 & 1 & 15 & 2 & 1 & 2 & 19 & 0 \\
\hline Elephant & 1 & 1 & 0 & 5 & 48 & 0 & 0 & 1 \\
\hline Flea & 0 & 0 & 0 & 0 & 0 & 55 & 1 & 0 \\
\hline Fly & 0 & 1 & 0 & 0 & 0 & 41 & 14 & 0 \\
\hline Fox & 7 & 0 & 42 & 0 & 0 & 0 & 7 & 0 \\
\hline Frog & 1 & 7 & 2 & 6 & 0 & 35 & 4 & 3 \\
\hline Gazelle & 2 & 4 & 0 & 8 & 3 & 1 & 35 & 2 \\
\hline Giraffe & 1 & 8 & 0 & 0 & 41 & 0 & 3 & 1 \\
\hline Goat & 2 & 2 & 6 & 42 & 1 & 1 & 1 & 1 \\
\hline Goldfish & 0 & 10 & 0 & 6 & 0 & 37 & 3 & 0 \\
\hline Gopher & 0 & 14 & 9 & 11 & 1 & 15 & 6 & 0 \\
\hline Gorilla & 25 & 0 & 5 & 4 & 22 & 0 & 0 & 0 \\
\hline Hippopotamus & 1 & 0 & 0 & 1 & 51 & 0 & 0 & 3 \\
\hline Horse & 0 & 4 & 12 & 2 & 11 & 0 & 27 & 0 \\
\hline Hummingbird & 0 & 10 & 2 & 0 & 0 & 34 & 10 & 0 \\
\hline Kangaroo & 0 & 5 & 13 & 2 & 11 & 0 & 24 & 1 \\
\hline Leopard & 27 & 1 & 2 & 0 & 1 & 1 & 23 & 0 \\
\hline Lion & 52 & 0 & 0 & 0 & 2 & 0 & 2 & 0 \\
\hline Lobster & 10 & 4 & 0 & 6 & 0 & 25 & 1 & 10 \\
\hline Mole & 0 & 8 & 0 & 13 & 0 & 28 & 4 & 3 \\
\hline Moose & 4 & 2 & 1 & 13 & 36 & 0 & 0 & 0 \\
\hline Mouse & 0 & 12 & 1 & 0 & 0 & 40 & 3 & 0 \\
\hline Octopus & 11 & 9 & 2 & 6 & 12 & 3 & 8 & 5 \\
\hline Ostrich & 0 & 5 & 1 & 17 & 12 & 1 & 18 & 2 \\
\hline Otter & 1 & 6 & 16 & 5 & 0 & 16 & 7 & 5 \\
\hline Owl & 3 & 5 & 40 & 0 & 1 & 4 & 2 & 1 \\
\hline $\mathrm{Ox}$ & 4 & 0 & 0 & 14 & 37 & 0 & 0 & 1 \\
\hline Panda & 1 & 29 & 7 & 2 & 10 & 2 & 0 & 5 \\
\hline Penguin & 0 & 17 & 13 & 3 & 1 & 9 & 2 & 10 \\
\hline Pig & 0 & 2 & 6 & 31 & 5 & 0 & 1 & 11 \\
\hline Polar Bear & 12 & $i$ & 1 & 1 & 40 & 0 . & 1 & 0 \\
\hline Rabbit & 0 & 10 & 2 & 0 & 0 & 8 & 36 & 0 \\
\hline Raccoon & 1 & 7 & 26 & 2 & 0 & 18 & 1 & 1 \\
\hline Rat & 4 & 1 & 5 & 6 & 2 & 27 & 10 & 1 \\
\hline Rhinoceros & 12 & 0 & 0 & 3 & 40 & 0 & 0 & 1 \\
\hline Seagull & 0 & 18 & 5 & 1 & 0 & 13 & 19 & 0 \\
\hline
\end{tabular}


Table 1 Continued

\begin{tabular}{lrrrrrrrr} 
& \multicolumn{7}{c}{} & \multicolumn{7}{c}{ Attribute } & & \\
\cline { 2 - 8 } \multicolumn{1}{c}{ Animal } & Fierce & Meek & Smart & Dumb & Large & Small & Fast & Slow \\
\hline Seal & 0 & 16 & 22 & 2 & 5 & 2 & 4 & 5 \\
Shark & 49 & 0 & 3 & 0 & 2 & 0 & 2 & 0 \\
Sheep & 0 & 37 & 2 & 9 & 0 & 4 & 1 & 3 \\
Snail & 0 & 2 & 0 & 1 & 1 & 13 & 0 & 39 \\
Sparrow & 0 & 7 & 3 & 1 & 0 & 31 & 13 & 0 \\
Squirrel & 0 & 8 & 13 & 2 & 0 & 14 & 19 & 0 \\
Tarantula & 36 & 1 & 0 & 0 & 2 & 10 & 0 & 7 \\
Tiger & 54 & 0 & 0 & 0 & 0 & 0 & 2 & 0 \\
Toad & 0 & 3 & 0 & 15 & 0 & 33 & 0 & 5 \\
Turkey & 0 & 2 & 6 & 36 & 1 & 4 & 2 & 3 \\
Walrus & 1 & 3 & 1 & 8 & 30 & 0 & 0 & 11 \\
Weasel & 2 & 1 & 19 & 8 & 0 & 13 & 10 & 1 \\
Whale & 1 & 0 & 0 & 0 & 53 & 0 & 0 & 0 \\
Wolf & 29 & 0 & 15 & 1 & 0 & 0 & 3 & 0 \\
Worm & 0 & 5 & 0 & 5 & 0 & 29 & 0 & 15 \\
Zebra & 1 & 13 & 5 & 4 & 9 & 0 & 22 & 0 \\
\hline
\end{tabular}

cases in which the frequencies do not total 56 resulted from some subjects' failing to select attributes for some animals. The frequencies are assumed to reflect the salience of the dimensions with respect to each animal. Fleas and buffaloes, for example, were almost exclusively associated with the size dimension, suggesting size to be a particularly salient attribute of them. Attribute selections for other animals, like penguins and squirrels, in contrast, were more varied.

The relationships between the salience ratings of the animals and their relative positions on the four underlying dimensions were evaluated by computing Pearson correlations between the frequency data and Holyoak and Mah's (1981) nomative magnitude ratings. With one exception, the resulting coefficients were all reliable beyond the .01 level $(\mathrm{df}=78)$, ranging from .57 to .76 for the positive adjectives ("fierce," "large," "smart," and "fast") and -.45 to -.80 for the negative adjectives. The exception was the nonsignificant -.13 correlation between the frequencies of "dumb" classifications and Holyoak and Mah's intelligence scale. The frequency with which attributes were chosen as the most salient of particular animals thus was relatively strongly related to their relative positions on the underlying, related dimension. The magnitudes of the correlations, however, indicated that attribute salience and relative magnitude ratings provide somewhat different information.

\section{EXPERIMENT 2}

This experiment evaluated the role of the association between particular stimuli and the dimensions on which they are compared. As noted earlier, a semantic priming interpretation of the congruity effect (Marschark \& Paivio, 1981) would predict its occurrence with the S.C paradigm only if the comparative dimension were particularly salient with respect to the to-be-compared stimuli. Following the pair "elephant whale," for example, the congruent comparative "larger" would be expected to produce a relatively fast response, and the specifically incongruent comparative "smaller" a relatively slow response, thereby producing a congruity effect. The effect would not be expected if the same pair were compared on a nonsalient dimension (such as intelligence), because neither the positive nor negative adjective would have a relative advantage.

On the basis of the correlational results from the normative study, size and ferocity were chosen as the dimensions of interest in this experiment. Several precautions, described below, were taken to ensure that the judgment task was comparable to Holyoak and Mah's (1981) and that subjects were unable to complete comparisons prior to presentation of comparative terms.

\section{Method}

Stimuli and Design. The salience norms were used to determine the degree of association of stimulus items with the adjectives "fierce," "meek," "large," and "small." The salient stimulus set was composed of four groups of eight pairs, each group highly associated with a different critical adjective. Thirty-two nonsalient stimuli similarly were selected on the basis of not being highly associated with particular adjectives. All stimuli had relative magnitudes congruent with the adjectives according to the Holyoak and Mah (1981) norms. In addition, 10 relatively smart and 10 relatively dumb animals, not differing appreciably in the salience of their ferocity or sizes, were selected and paired using the salience and magnitude norms. These were to serve as filler items in the judgment task to increase subjects' uncertainty concerning the dimension of the comparison. In all sets, items were paired such that the two members would be relatively close in magnitude but sufficiently distinct to allow unambiguous decisions in all cases. The average magnitude difference for each sublist was approximately 1.50 according to the Holyoak and Mah norms. Examples of salient and nonsalient stimuli are presented in Table 2.

Two lists of test stimuli were constructed. These contained the same stimulus pairs, but in two different random orders and with the counterbalanced, left-right positions of the items 
Table 2

Examples of Salient and Nonsalient Stimuli of Experiment 2 as Paired With Comparatives

Dimension

\begin{tabular}{|c|c|c|c|}
\hline \multicolumn{2}{|c|}{ Salient Relationships } & \multicolumn{2}{|c|}{ Nonsalient Relationships } \\
\hline Ferocity & Size & Ferocity & Size \\
\hline $\begin{array}{l}\text { lion-eagle (fierce) } \\
\text { penguin-dove (meek) }\end{array}$ & $\begin{array}{l}\text { elephant-buffalo (large) } \\
\text { canary-flea (small) }\end{array}$ & $\begin{array}{l}\text { raccoon-badger (fierce) } \\
\text { hummingbird-antelope (meek) }\end{array}$ & $\begin{array}{l}\text { shark-dinosaur (large) } \\
\text { tarantula-weasel (small) }\end{array}$ \\
\hline
\end{tabular}

reversed. Each list contained 74 pairs. In addition to the 10 filler (intelligence) pairs, there were 32 salient and 32 nonsalient pairs. These were the four pairs constructed for each adjective combined both with that term and its polar opposite. Each list thus composed a 2 (salient vs. nonsalient) by 2 (dimension: ferocity vs. size) by 2 (relative magnitude: fierce or large vs. meek or small) by 2 (congruent vs. incongruent comparative), within-subjects design.

Since the congruity effect is generally assumed to depend on the extremity of stimulus scale position, care was taken to ensure that there were no overall differences in size or ferocity ratings between salient and nonsalient stimuli. Using Holyoak and Mah's (1981) norms, stimuli were selected so that the mean fierceness ratings of salient and nonsalient stimuli were 5.28 $(\mathrm{SD}=2.58)$ and $5.68(\mathrm{SD}=2.34)[\mathrm{t}(62)=1.22]$, respectively. Their mean size ratings were $4.81(\mathrm{SD}=2.39)$ and $4.95(\mathrm{SD}=$ 2.37) $[\mathrm{t}(62)=1.02]$, respectively. Although the standard deviations indicated approximately equal scale positions of the salient and nonsalient stimuli, this was tested explicitly for both dimensions. For each stimulus item, the absolute value of its deviation from the appropriate (salient or nonsalient) set mean was obtained, and these scale extremity scores were then standardized. T tests using these scores indicated that the extremity of salient and nonsalient items did not differ significantly on either dimension [fierceness, $t(62)=.86$; size, $t(62)=.20$ ]. Further, the fierceness and size stimuli were equally extreme on their respective dimensions $[t(63)=.17]$.

All stimuli were typed in IBM Orator capitals and presented in a tachistoscope.

Procedure. Each subject was instructed in the S-C judgment paradigm and was given 6 practice trials, 1 with each of the six possible comparatives, followed by the 74 test trials. Each trial began with a 1-sec exposure of a fixation point that served as a ready signal. This was followed by the stimulus pair, which remained in view for $1 \mathrm{sec}$ before being replaced by one of the six comparatives. The relatively short $1-\sec$ stimulus exposure was selected both because it was used by Holyoak and Mah (1981) and because pilot testing had shown it to be sufficient for subjects to encode the stimuli but not to complete the comparisons of them prior to presentation of the comparative. Nevertheless, it is still possible that some subjects were able to complete some comparisons during the $1-\mathrm{sec}$ interval. It may seem that this would have been most likely to occur on the most salient dimensions of pairs. Completed comparisons, however, would reduce the magnitude of congruity effects and thus work against the prediction of higher effects with salient as compared to nonsalient stimuli. In addition, completing comparisons on any substantial number of trials would also reduce mean reaction times relative to other trials. Insofar as no overall reaction time difference was found between salient and nonsalient trials, it seems unlikely that completed comparisons could have had any major role in producing the congruity effects observed.

The comparative, when presented, remained visible for 4 sec. During that time, subjects pushed one of two buttons (positioned under their right and left thumbs) corresponding to whether their response was the animal that had been on the right or the left. Both speed and accuracy were stressed. Responses and reaction times from the onset of the comparative were recorded and printed by a modular, solid state timing apparatus interfaced with the tachistoscope.

Subjects. The subjects were 12 introductory psychology students participating to receive credit toward a course requirement.

\section{Results and Discussion}

The 10 intelligence comparisons were not scored. The average error rates for salient and nonsalient stimuli were $19 \%$ and $15 \%$, respectively. Although rather high compared to those obtained with C-S judgment paradigms, these error rates were approximately the same as those obtained by Holyoak and Mah (1981) and appear to be due to the difficulty of the task. Importantly, no congruity effects were observed in the error data, ruling out any simple response-bias account of the reaction time congruity effects (Marschark \& Paivio, 1981). Mean correct reaction times were calculated and analyzed using a 2 (salience) by 2 (dimension) by 2 (comparative) by 2 (relative magnitude) analysis of variance. An alpha level of .05 was adopted, but, in fact, all significant effects reached a level of at least 01 .

The overall congruity effect (i.e., Comparative by Relative Magnitude interaction) was highly reliable $[F(1,11)=24.79$, MSe $=87,319]$, as was the (threeway) interaction of the congruity effect with stimulus salience $[F(1,11)=22.63, \mathrm{MSe}=95,333]$; the latter interaction is depicted in Figure 1. The magnitude of the effect for the salient pairs was $212 \mathrm{msec}$, whereas that for the nonsalient pairs was less than $1 \mathrm{msec}^{3}$ This finding was exactly as predicted from the semantic

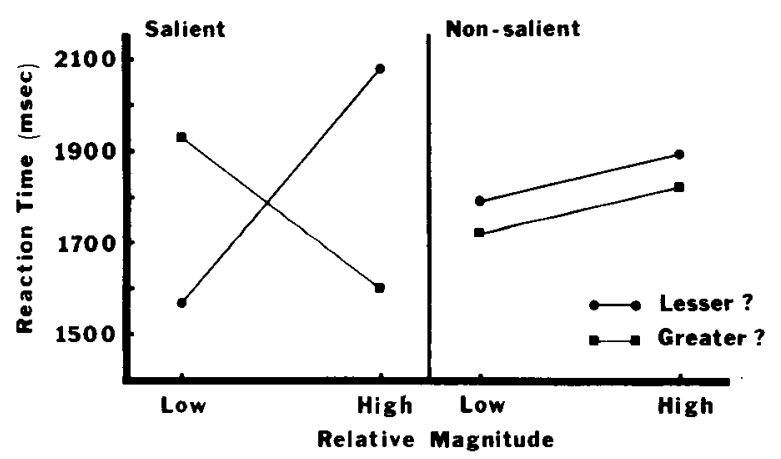

Figure 1. Mean reaction time data for choosing animals with lesser or greater magnitudes, given salient or nonsalient pairings of stimuli and comparative questions (Experiment 2). 
priming interpretation of the congruity effect (Marschark, 1982; Marschark \& Paivio, 1981, Note 1) and reconciles the conflicting results of Marschark and Paivio (1979, Experiment 2) and Holyoak and Mah (1981).

Overall, size comparisons were made faster than ferocity comparisons $[\mathrm{F}(1,11)=19.68, \mathrm{MSe}=408,783]$. This was qualified by interactions with salience $[\mathrm{F}(1,11)$ $=9.87, \mathrm{MSe}=42,238]$ and relative magnitude $[\mathrm{F}(1,11)$ $=12.57, \mathrm{MSe}=102,399 \mathrm{]}$, resulting from the difference between size and ferocity comparisons being greater for salient than for nonsalient pairs and greater for lowrelative-magnitude than for high-relative-magnitude pairs.

The main effect of dimension could be accounted for in several ways. For example, the finding is consistent with Paivio's (1978) suggestion that symbolic judgments of both size and ferocity involve the comparison of imaginal codes, but that size information is more directly available. Although it is not entirely clear how that position would account for the obtained two-way interactions, it presumably would entail some interface of the comparison "mechanism" with subjects' specific knowledge of the stimuli through associative links in the imagery and/or verbal systems. A stimulusspecific interface also would be needed to extend Holyoak and Mah's (1981) interpretation of their reliable dimension effect to the present interactions. They suggested that the main effect was likely to be due to people's having "more precise knowledge of magnitude for some dimensions, such as size, than for others" (Holyoak \& Mah, 1981, p. 201). To account for the related interactions as well, such precision would have to be attributed not just to knowledge of dimensions, but also to magnitude information for particular animals (or other stimuli) on particular dimensions. In these terms, this interpretation, as well as the preceding one, clearly requires some semantic priming mechanism comparable to that of Marschark and Paivio (1981).

Finally, it is noteworthy that a reliable lexical marking effect was not obtained here $[F(1,11)=1.43$, MSe $=181,794]$, although one was obtained by Holyoak and Mah (1981). The present finding is consistent with the prediction from the expectancy hypothesis that congruity and lexical marking should be mutually exclusive effects (Marschark \& Paivio, 1979). The assumption, at least for single-dimension comparisons, was that the activation induced by the C-S paradigm (producing the congruity effect) offsets the usual advantage of positive, or unmarked adjectives over their negative, or marked counterparts (i.e., the lexical marking effect). That is, activating information in memory on the basis of a particular comparative term logically requires that term already to have been analyzed. The S-C paradigm, in contrast, usually does not yield congruity effects, but the requirement of a speeded response following presentation of the comparative typically does produce a reliable marking effect. From this position, Holyoak and Mah's (1981) demonstration of both congruity and lexical marking effects could be accounted for as reflecting the summative effect of some salient pairings of stimuli and comparatives (contributing to a congruity effect but not to a lexical marking effect) and some nonsalient pairings (contributing to a lexical marking effect but not to a congruity effect). This interpretation is entirely post hoc, however, and fails to account for the lack of a reliable lexical marking effect with the nonsalient pairings in the present experiment. Given the inconsistency and even occasional reversal of the lexical marking effect (e.g., Marschark \& Paivio, 1979, Experiment 3; Wallis \& Audley, 1964, Experiment 1), its occurrence in symbolic comparisons clearly is in need of further investigation.

\section{GENERAL DISCUSSION}

The present experiments demonstrated that the relative salience of an attribute with respect to to-becompared animal stimuli can play an important role in symbolic comparisons. Overall, reaction times between magnitude comparisons on salient and nonsalient dimensions did not differ reliably. Reiative to judgments of animals on dimensions not strongly related with them, however, relative size and ferocity judgments were facilitated when those dimensions were perceived as highly characteristic of the animals and the comparative was congruent with the relative position of the stimuli on the dimension. Reaction times were slowed when the dimension was salient but the comparative was incongruent with the relative position of the stimuli.

The demonstration of a reliable congruity effect in the S-C paradigm both here and in Holyoak and Mah's (1981) study represent counterexamples to a general pattern in the relevant literature showing robust congruity effects to be obtained only when the comparative precedes the stimulus pair (see Marschark \& Paivio, 1979, for a review). This finding need not, however, "disconfirm any model that claims that the locus of the congruity effect is entirely in the initial encoding stage, as the expectancy hypothesis of Marschark and Paivio (1979) apparently does" (Holyoak \& Mah, 1981, p. 203). The initial statement of the expectancy hypothesis stated only that the comparative in the C-S paradigm creates an expectancy that would not be induced if it were presented after the stimulus pair (Marschark \& Paivio, 1979, p. 176). The fact that stimuli can create expectancies for comparatives on particularly salient dimensions appears to indicate a more flexible encoding process than was originally assumed, rather than its irrelevance to the production of congruity effects. In any case, this result is consistent with Marschark and Paivio's (1981; see also Banks, Mermelstein, \& Yu, 1982) elaboration of the expectancy hypothesis and their suggestion that the congruity effect arises from the activation of information from long-term memory following stimulus presentation.

Another important aspect of the present findings was that when scale position was controlled, manipulating the salience of stimuli-attribute relationships was suf- 
ficient to produce a very large congruity effect or to completely eliminate it. This appears to conflict with the frequent assumption that congruity effects are, in large measure, dependent on the extreme scale positions of the stimuli, like the sizes of elephants and fleas or the intelligence of dolphins and turkeys (e.g., Banks \& Flora, 1977; Holyoak, 1978). From the priming view of congruity effects, in contrast, it is the strength of S-C associations rather than the extremity of scale positions per se that controls activation of the magnitude information required for the comparison. Extremity may only appear to affect congruity interactions because of its confound with salience. Although this variable has yet to be examined empirically in symbolic comparisons (but see further discussion below), the present results clearly indicate that extremity is not sufficient to produce congruity effects.

Another important aspect of the priming interpretation of congruity effects concerns its locating the effect in the encoding of stimuli rather than the comparison stage of symbolic comparisons (cf. Banks \& Flora, 1977; Holyoak, 1978; Holyoak \& Mah, 1981). According to Marschark's (1982) elaboration of this position, the congruity effect is just one consequence of a flexible interface between the external world and memory, that is, the individual's familiarity with aspects of a particular situation and expectations about the task (see Logan, 1980). Together, these allow a directed activation of semantic memory. Encoding in the bipolar comparison task therefore need not entail "complete activation of all of the information associated with a concept, including its values as all possible attribute dimensions," as Holyoak and Mah (1981, p. 203) have claimed. In fact, it is precisely because only a subset of that information is activated at any given time, and is sometimes incorrect, that the congruity effect is assumed to occur.

Closely related to this as well as the previous point, is one further consequence of the priming position. Logan (1980), in discussing attention and automaticity in cognitive processing, pointed out several similarities between Stroop tasks and lexical decision tasks. Most important for the present purposes, he noted that both initially involve automatic processing that later can be superseded or altered by attentional processes and entail "a temporally extended blend of evidence from past associations and current contingencies" (Logan, 1980 , p. 542). These are all also descriptive of the bipolar comparison task. The congruity effect, for example, reflects an initial automatic activation of semantic memory that sometimes (i.e., for incongruent stimulus comparative pairings) has to be redirected. The effect's interaction with the salience of associated attributes in Experiment 2 parallels similar findings in both Stroop tasks (Dalrymple-Alford, 1972; Lupker, 1979) and lexical decision tasks (Neely, 1976; Schuberth \& Eimas, 1977). Interactions of the congruity effect with the size of the category of to-be-compared stimuli in studies by Marschark and Paivio (Note 1) and Marschark and Azmitia (Note 2) further coincide with effects obtained in the Stroop-like interference task of Logan and Zbrodoff (1979).

Marschark and Paivio (Note 1) found the magnitudes of congruity effects to decline monotonically as the proportion of animals (as opposed to "other things") in their stimulus lists declined from 1.00 to .50 to .25 . Similarly, Marschark and Azmitia (Note 2) obtained reliable congruity effects with animal stimuli but not "other things" in bipolar comparisons by second-graders, sixth-graders, and high school students. University students yielded reliable effects with both stimulus sets, although that with animals was $20 \%$ larger. Logan and Zbrodoff (1979) presented subjects with the to-benamed words ABOVE and BELOW, positioned either above or below a fixation point. When conflicting stimuli were relatively rare (20\%), they were responded to more slowly than compatible stimuli. When they occurred on $80 \%$ of the trials, however, they were responded to faster than the $(20 \%)$ compatible stimuli.

The above findings all appear to indicate the flexible, probabilistic nature of stimulus expectancies and encoding in symbolic processing tasks. Further, they suggest that congruity effects, Stroop effects, and the patterns of reaction times observed in lexical decision tasks all involve some common cognitive process. Within this context and with the new emphasis on encoding in symbolic comparisons suggested by the present study, it should now be possible to more clearly isolate and explain the separate stages of retrieving attribute information and actually using that information in making comparative judgments.

\section{REFERENCE NOTES}

1. Marschark, M., \& Paivio, A. Expectancy, associative priming, and the locus of semantic congruity effects in comparative judgments. Unpublished manuscript, 1980.

2. Marschark, M., \& Azmitia, M. M. Congruity and the development of associative priming. Paper presented at the annual meeting of the Psychonomic Society, Philadelphia, November 1981.

\section{REFERENCES}

BANK8, W. Encoding and processing of symbolic information in comparative judgments. In $\mathrm{G}$. Bower (Ed.), The psychology of learning and motivation (Vol. 11). New York: Academic Press, 1977.

Banks, W., \& Flora, J. Semantic and perceptual processes in symbolic comparisons. Journal of Experimental Psychology: Human Perception and Performance, 1977, 3, 278-290.

Bank8, W., Fujil, M., \& Kayra-Stuart, F. Semantic congruity effects in comparative judgments of magnitudes of digits. Journal of Experimental Psychology: Human Perception and Performance, 1976, 2, 435-447.

Bank8, W., Mermelstein, R., \& Yu, H. K. Discriminations among perceptual and symbolic stimuli. Memory \& Cognition, $1982,10,265-278$.

Dalnymple-Alford, E. C. Associative facilitation and interfer- 
ence in the Stroop color-word task. Perception \& Psychophysics, $1972,11,274-276$.

HolyoAK, K. Comparative judgments with numerical reference points. Cognitive Psychology, 1978, 10, 203-243.

Holyo^k, K., \& MAн, W. Semantic congruity in symbolic comparisons: Evidence against an expectancy hypothesis. Memory \& Cognition, 1981, 9, 197-204.

Holyoak, K., \& Walker, J. Subjective magnitude information in semantic orderings. Journal of Verbal Learning and Verbal Behavior, 1976, 15, 287-299.

Kosslyn, S. M., Murphy, G. L., Bemegderfen, M. E., \& Feingtein, $K$. J. Category and continuum in mental comparisons. Journal of Experimental Psychology: General, 1977, 106, 341-376.

LoaAN, G. D. Attention and automaticity in Stroop and priming tasks: Theory and data. Cognitive Psychology, 1980, 12, 523553.

Logan, G. D., \& ZBrodoff, N. J. When it helps to be misled: Facilitative effects of frequency of conflicting stimuli in a Stroop-like task. Memory \& Cognition, 1979, 7, 166-174.

LUPKER, S. J. The semantic nature of response competition in the picture-word interference task. Memory \& Cognition, 1979, 7, 485-495.

Margchark, M. Expectancy, equilibration, and memory. In J. Yuille (Ed.), Imagery, memory, and cognition: Essays in tribute to Allan Paivio. Hillsdale, N.J: Erlbaum, 1982.

Marschark, M., \& Paivio, A. Semantic congruity and lexical marking in symbolic comparisons: An expectancy hypothesis. Memory \& Cognition, 1979, 7, 175-184.

Margchark, M., \& Paivio, A. Congruity and the perceptual comparison task. Journal of Experimental Psychology: Human Perception and Performance, 1981, 7, 290-308.

MoYen, R., \& LANdauen, T. The time required for judgments of numerical inequality. Nature, 1967, 215, 1519-1520.

NeELY, J. H. Semantic priming and retrieval from lexical memory: Evidence for facilitatory inhibitory processes. Memory \& Cognition, 1976, 4, 648-654.
Paivio, A. Mental comparisons involving abstract attributes. Memory \& Cognition, 1978, 6, 199-208.

Schubenth, R. E., \& Eimas, P. D. Effects of context on the classification of words and non-words. Journal of Experimental Psychology: Human Perception and Performance, 1977, 3, 27-36.

Wallis, C., \& Audley, R. Response instructions and the speed of relative judgments: II. Pitch discrimination. British Journal of Psychology, 1964, 55, 133-142.

\section{NOTES}

1. Most investigations of the congruity effect have been concerned primarily with whether symbolic comparisons involve discrete, linguistic codes (e.g., Banks \& Flora, 1977; Banks, Fujii, \& Kayra-Stuart, 1976) or analogue magnitude codes (Holyoak, 1978; Kosslyn, Murphy, Bemesderfer, \& Feinstein, 1977). The expectancy hypothesis is atheoretical in this regard, relating to the access of magnitude information at the time of encoding, regardless of the nature of the mental representation of that information.

2. "Expectancy" is not intended to imply a necessarily conscious or attentional component in this process. See Marschark (1982) for a more complete discussion of this point.

3. Congruity effect magnitudes throughout this paper are based on the most common formula $C E=[(M G+U L)-(U G+$ $M L)] / 4$, where $M$ and $U$ refer to marked and unmarked comparatives, respectively, and $G$ and $L$ refer to greater and lesser relative magnitudes, respectively. Holyoak and Mah's (1981) effects were calculated as the overall difference between congruent and incongruent pairings and thus are twice as large as they would be if calculated according to the method used here.

(Received for publication August 4, 1982; revision accepted September 24, 1982.) 